\title{
To Conclude
}

I have now reached the end of my book, as have you, dear reader. The things that had been on my mind more than 15 years of my career as a futurist have now been more or less written down and passed forward. I hope that this read was as rewarding to you as the writing process had been to me.

One piece of advice for efficient communication is the following:

1. Assure what you are going to say.

2. Say it.

3. Explain what you just said.

I have now come to phase three. I will sum up what I have said on the previous pages. This is the summary:

Future thinking can be used for anticipation, innovation and communication. The central factor in the future is you. You can influence its course with your own actions and by not acting. Even when you cannot influence the future, you should prepare for the different possibilities.

Here it is. My first (non-academic) book.

Now it is time to do some laundry. 